\title{
Violência contra a Mulher e Atendimento Psicológico: o que Pensam os/as Gestores/as Municipais do SUS
}

Violence against Women and Psychological Treatment: The

View of Municipal Administrators of the Public Health

System - SUS

Madge Porto

Universidade

Federal de

Pernambuco

"Este artigo foi escrito a partir das falas dos gestores/as entrevistados/as para a realização da minha dissertação de mestrado (PIPASC/DMS/UFPE com bolsa da CAPES) e do artigo produzido no Programa Interinstitucional de Treinamento em Metodologia de Pesquisa em Gênero, Sexualidade e saúde Reprodutiva (MUSA/ISC/UFBA com financiamento da Fundação FORD)."

Agradecimento especial ao prof. M. Sc. Francisco Pereira (UFAC) pelo apoio e pelas contribuições. 


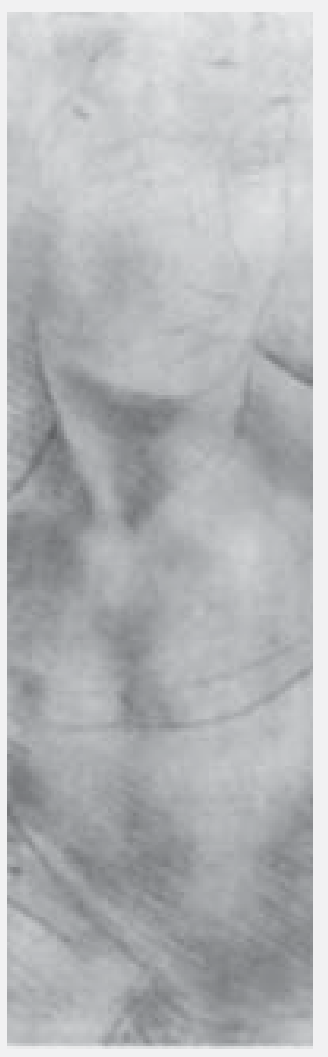

Resumo: Este estudo tem como objetivo apresentar o que pensam os/as gestores/as municipais do Sistema Único de Saúde - SUS - sobre o atendimento psicológico às mulheres em situação de violência. Como resultado, pode-se destacar que existe uma necessidade, percebida pelos/ as gestores/as, do trabalho de psicólogas/os no contexto da violência contra a mulher. Este é entendido como uma intervenção fundamental. Entretanto, o atendimento psicológico aparece de forma isolada, desvinculado da política municipal de saúde mental.

Palavras-chave: violência contra a mulher, Psicologia, saúde mental, administração municipal e sistema de saúde.

Abstract: The aim of this study is to present what the municipal
administrators think about the Brazilian public health system in regard to
psychological attention given to women in situation of violence. One
result points the need, as perceived by the administrators themselves, for
the work of psychologists in the context of violence against women. This
is understood as a fundamental intervention. However, psychological
treatment appears in insolated instances and is not linked to any broad-
scope mental health municipal policy. Key words:violence against women; Psychology; mental health; municipal administration and health system.

O atendimento psicológico realizado durante oito anos, em ambulatórios do SUS de uma cidade da Região Metropolitana do Recife RMR - (PE - Brasil), possibilitou a observação, não sistemática, de como as mulheres procuram o sistema de saúde e quais as suas motivações. Por outro lado, também se observou como esse sistema recebe essas mulheres e quais as condições de atendimento oferecidas. Nesse contexto, dois aspectos se destacam: a convivência das mulheres com situações de violência e a invisibilidade dessa questão para os/as profissionais que realizam o atendimento e para os gestores/as que pensam e implementam as ações para essas mulheres. No atendimento de psicologia, a questão aparece por trás de sintomas como depressão e ansiedade; no entanto, com muita dificuldade, a vivência de tal situação é revelada. Nesse momento, aparecem questões como: O que fazer? Como intervir?
O que orientar? Que ela saia de casa? E vá para onde? Quem poderia ajudá-la?

Na falta de uma oportunidade concreta para a mudança de sua situação, as mulheres permanecem convivendo com a violência e voltando para as consultas com as queixas: 'agonia', insônia, impaciência, angústia, dentre muitos outros sintomas, e os serviços de saúde continuam medicando ou encaminhando para o atendimento psicológico.

Essa situação motivou alguns questionamentos: o que pensam gestores e gestoras desse sistema de saúde sobre as mulheres em situação de violência? Existem ações planejadas para estas? Qual o papel da/o profissional da Psicologia nesse contexto?

Para tentar responder a essas perguntas, formulou-se um estudo - na área de saúde 
... otermo

violência contra a

mulher adquire um

sentido

instrumental,

tornando-se uma

categoria política

cunhada pela

abordagem

feminista para

denunciar as

desigualdades na

relação homem/

mulher.
1 A expressão 'homens autores de violencia' aparece em substituição à expressão 'agressores', com base nos estudos do psicólogo Fernando Acosta, do Instituto Noos, do Rio de Janeiro - RJ, fundamentados na compreensão que 'agressores' enfoca apenas 0 aspecto biopsicológico, que se apresenta como limitante para o entendimento de um fenomeno tão complexo como a violência de gênero contra a mulher. Para ele. utilizando a expressão 'homens autores de violência'; o fenômeno passa a ser compreendido como social, político e cultural, ampliando a percepção do problema e as possibilidades de intervenção. Esses argumentos foram apresentados no Seminário Gênero e Masculinidade, que foi realizado em 08/10/2003, em Rio Branco - AC. coletiva, mais especificamente, de políticas públicas de saúde - com o objetivo de investigar o que pensam gestores/as de Secretarias Municipais de Saúde acerca da saúde da mulher em situação de violência. De uma forma mais específica, seria: conhecer as representações desses/as gestores/as sobre a saúde da mulher em situação de violência e investigar o papel dessas representações enquanto determinantes de decisões políticas concernentes a ações de saúde dirigidas a essas mulheres (Porto, 2002; Porto et al., 2003).

Os relatos desses/as gestores/as expressaram representações de natureza diversas; no entanto, um aspecto será abordado neste artigo: as representações sobre a mulher em situação de violência e a intervenção psicológica.

\section{A violência contra a mulher e as conseqüências para a saúde}

Desde 1991, a violência contra a mulher é reconhecida pela Organização Pan-Americana de Saúde - OPS - como causa de adoecimento das mulheres, sendo considerada uma questão de saúde pública (Heise; Pitanguy e Germain, 1994; Camargo, 2000).

A literatura traz vários aspectos desse tipo de violência, desde aspectos conceituais e de parâmetros até tipificações. Dependendo do tipo de enfoque do estudo, a violência contra a mulher aparece como resultado do conflito de gênero. É importante destacar que o conceito de gênero utilizado neste estudo é o de Heilborn (1991), que se refere à distinção entre atributos culturais alocados a cada um dos sexos, destacando "... a perspectiva relacional e sistêmica que domina o jogo de construção de papéis e identidades para ambos os sexos" (p. 29). Enfatiza, ainda, que a noção de gênero é um "... elemento constitutivo da razão simbólica" (p.29). A violência contra a mulher também é referida como violência doméstica, familiar, sexual, psicológica, física, dentre outras classificações. Estas se relacionam ou estão contidas umas nas outras, entretanto, pode-se considerar que a condição de ser mulher, construída socialmente, determina aspectos de vulnerabilidade a um tipo específico de violência: violência contra a mulher. Esta se caracteriza por ser uma violência cometida por um homem contra uma mulher, sendo determinada pelos modelos culturais do que é ser homem, do que é ser mulher e de qual a função da violência nas relações interpessoais e de poder. Essa condição de gênero determina a existência desse tipo de violência, mais freqüentemente, no espaço socialmente estabelecido para as mulheres: o espaço privado, a família, o domicílio. Nesse caso, o agressor deixa de ser um estranho e passa a ser alguém com quem a mulher tem alguma ligação afetiva: parceiro, pai, padrasto ou outro familiar (Giffin, 1994), sendo que parceiros ou ex-parceiros são os autores da violência ${ }^{1}$ em aproximadamente $70 \%$ das denúncias registradas nas Delegacias de Defesa da Mulher (DDM) (D'Oliveira e Schraiber, 2000). Para Brandão (1998),

... o termo violência contra a mulher adquire um sentido instrumental, tornando-se uma categoria política cunhada pela abordagem feminista para denunciar as desigualdades na relação homem/mulher. No âmbito dessa relação, as posições de vítima (como atributo do feminino) e agressor (como atributo do masculino) tendem a ser enfatizadas (p. 58, grifos da autora).

Muitas dessas agressões levam imediatamente ao óbito, enquanto outras representam "situações crônicas de vida" (Schraiber et al., s/d, p. 4), não se apresentando como fatais, mesmo quando, muitas vezes, são de alta gravidade, o que causa, dessa forma, repercussões nos índices de morbidade, que parecem não mobilizar, de uma forma geral, ações específicas do sistema de saúde. Entretanto, por se apresentarem de “...caráter sistemático e repetitivo" (Schraiber et al., s/d, 
p.4), e não episódico, as conseqüências da situação de violência para os serviços de saúde são significativas. Da violência, derivam sofrimentos permanentes e cronificados, aumentando, sobremaneira, a demanda pelos serviços de saúde (Schraiber et al., s/d), que têm, muitas vezes, o encaminhamento para um atendimento psicológico.

Para Schraiber e D'Oliveira (1999), a violência contra a mulher, inicialmente, foi percebida como uma doença que requeria uma intervenção baseada na racionalidade biomédica, desde que identificada com uma base anatomo-patológica, objetiva e visível que permitisse uma justificativa para a intervenção - como acontece no Judiciário, pois, não existindo a 'materialidade' da prova, não há crime (Vargas, 2002). Caso contrário, a queixa não era considerada parte das ações em saúde, sendo citada como parte da ordem do social e/ou do psicológico, o que as desqualificava para uma intervenção médica. As autoras afirmam, no entanto, que essa demanda precisa ser tomada como uma questão de saúde que aguarda uma intervenção adequada, pois a forma de intervenção será determinada a partir do modo como a violência doméstica contra a mulher é compreendida e acolhida. Para Schraiber et al. (s/d),

[...] além do fato de que recentes dados de estudos internacionais demonstram a grande quantidade de repercussões para a saúde pelo fato de se viver em situação de violência, a violência é um problema: de saúde, de organização e produção dos trabalhos em saúde, de programas de atenção e prevenção, de políticas (p.3).

No entanto, a questão da violência não deve ser tomada como de competência única dos serviços de saúde, numa forma de substituição das ações da Justiça. A violência se refere a um "... conjunto amplo de problemas, cujas repercussões no setor saúde e as possibilidades ou os limites de intervenção são bem diferentes" (Schraiber et al., s/d, p.3). A promoção à saúde e a assistência médica às mulheres que vivem em situação de violência são aspectos, dentre vários outros, que representam a possibilidade de realização de direitos constituídos que garantam melhores condições de cidadania. Ainda segundo as autoras, essa é uma reflexão que se enquadra nas discussões de políticas públicas que favoreçam a qualidade de vida, e não só nas discussões restritas ao movimento feminista, precursor do debate e das propostas com relação às questões da saúde da mulher em situação de violência.

A literatura especializada vem demonstrando associação de risco entre a experiência da violência e o desenvolvimento de agravos, de ordem física e mental, os quais repercutem na diminuição de "anos saudáveis de vida" das mulheres (D'Oliveira e Schraiber, 2000). As conseqüências da violência doméstica são agravos que vão desde um empurrão leve até à morte. Sendo de natureza crônica, a agressão à mulher vai além dos traumas e dos agravos visíveis (quebraduras, torções), estando associada a problemas como: baixo peso ao nascer (dos filhos), problemas gastrintestinais (úlceras, colites), queixas ginecológicas (abortos, gravidezes indesejadas e repetidas em curto espaço de tempo, doenças sexualmente transmissíveis, hemorragias, lesões, dores pélvicas, leucorréias repetidas e infecções), abuso de álcool e outras drogas, queixas vagas, depressão, insônia, suicídio, sofrimento mental, lesões e problemas crônicos, como distúrbios alimentares, dores abdominais e de cabeça, e até artrite, hipertensão e doenças cardíacas (Camargo, 2000; Franco, 2000; Schraiber e D'Oliveira, 1999; D'Oliveira e Schraiber, 2000; Schraiber et al., s/d).

As mulheres que sofrem violência procuram mais os serviços de saúde, porém os/as profissionais ainda não identificam e/ou registram a violência nos prontuários como parte da rotina do atendimento. Entretanto, parece existir uma diferenciação no
"... conjunto amplo de problemas, cujas repercussões no setor saúde e as possibilidades ou os limites de intervenção são bem diferentes" 
encaminhamento dos casos: as situações de violência doméstica ou sexual têm indicação para serviços de saúde mental, enquanto os outros tipos de violência - como, por exemplo, a violência urbana - não têm a mesma indicação (Schraiber e D'Oliveira, 1999). Essa atitude sugere que os/as profissionais percebem que a condição em que se deu a violência ocasionará diferentes repercussões, mesmo não sabendo ainda como lidar com a questão. Essa intervenção, muitas vezes, pode determinar o que Schraiber et al. (s/d) chamam de psicologização do problema da violência, que também é uma forma de não enfrentamento da questão pelos serviços de saúde.

Esse ponto da "psicologização" torna-se relevante, pois coloca um desafio para as/os psicólogas/os. A situação de violência contra a mulher apresenta, para os serviços de saúde, um problema para o que os modelos antigos de intervenção não dão uma resposta eficiente, e a solução é "jogá-lo" para a/o psicóloga/o - "que resolve coisas complicadas", "que entende de problemas da cabeça dessas mulheres problemáticas" - como última alternativa para o caso, sendo essa uma intervenção isolada, sem vinculação com outras questões da saúde, como a saúde da mulher e a saúde mental. Por outro lado, a atuação da Psicologia se faz necessária dentro do conjunto de intervenções para o enfrentamento do problema.

Considerando que este estudo tem o objetivo de investigar as representações de gestores/ as sobre a violência contra a mulher e a intervenção psicológica, torna-se indispensável tecer algumas considerações sobre o que se entende por representação e suas interrelações com as normas e a prática.

O conceito de representação é complexo, pois aborda algo da interação entre o social e o subjetivo, e pode ser definido de vários modos.
A Psicologia social acumula um importante conhecimento acerca das representações sociais. Para Guareschi (1995), em um comentário sobre a definição de representação para Jodelet, " a representação é um ato do pensamento por meio do qual o sujeito se relaciona com o objeto" (p.215). Já Spink (2003) define representações sociais como:

“... forma de conhecimento prático - o saber do senso comum - que tem por função estabelecer uma ordem que permita aos indivíduos orientarem-se em seu mundo social e material e possibilitar, dessa forma, a comunicação com os membros de um mesmo grupo" (p.40).

Em um estudo sobre as representações sociais e a esfera pública, Jovchelovitch (2000) afirma que " ... representações sociais são ... fenômenos simbólicos produzidos na esfera pública" (p.40).

Segundo Bock (1995), “As representações, veiculadas pela linguagem, são dados empíricos e, portanto, o ponto de partida para a análise da consciência" (p. 282).

Já Bozon (1995) discute a relação das práticas, normas e representações, definindo como representações a:

[...] camada mais antiga, mas também a mais estável e a mais implícita da visão de mundo dos indivíduos. Nas representações, encontramse categorias de classificação, imagens, símbolos que organizam a relação dos indivíduos [...] Essa visão de mundo se apresenta, com freqüência, como natural, não exigindo qualquer justificativa [...] (Bozon, 1995, p.123).

No presente estudo, "representação" está sendo entendida como o aspecto subjetivo, simbólico, que se expressa através da fala sobre a saúde da mulher em situação de violência e a intervenção psicológica, ou seja, como os/as gestores/as representam essa temática. 
Em estudos realizados dentro do escopo teórico da saúde coletiva, saúde pública, e, mais especificamente, das políticas públicas de saúde, as representações parecem ser um aspecto ainda considerado secundário por ser "subjetivo" e, assim, menos importante, quando o que está em questão é algo "objetivo", como uma política de saúde. Entretanto, este estudo pretende mostrar que o aspecto das representações, que se apresenta como subjetivo, torna-se relevante, pois as questões subjetivas também podem determinar atitudes e o estabelecimento de prioridades e ações das políticas da saúde.

\section{Descrevendo as formas de acesso às informações}

Foram escolhidos dezoito gestores/as de três dos catorze municípios da Região Metropolitana do Recife -RMR (PE - Brasil) incluídos há mais tempo em Gestão Plena do Sistema Municipal de Saúde. Essa escolha se deu porque, a partir da Norma Operacional Básica de 1996 - NOB96 -,os Municípios que se instituíram em Gestão Plena passaram a ter, como uma de suas atribuições, a responsabilidade de responder às demandas de saúde da população (Lacerda et al., 1998), contando, para isso, com autonomia para a formação da agenda (programa de governo) e para a formulação e a implementação das políticas de saúde. Assim, os Municípios poderiam implementar ações avaliadas como relevantes ou prioritárias, mesmo que não fizessem parte das propostas e agendas dos níveis estadual e nacional. Para garantir o anonimato dos/as gestores/as que se dispuseram a colaborar com o estudo, seus nomes foram preservados. A identificação dos relatos será feita com nomes fictícios.

A escolha por gestores/as municipais se deve à descentralização da gestão na saúde, diretriz instituída pelo SUS, que possibilita decisões políticas a partir da realidade local.
Os instrumentos para a coleta de informações utilizadas neste artigo foram: 1) questionário fechado, para caracterizar o/a informante; 2) entrevista semi-estruturada a partir dos temas violência doméstica e saúde da mulher, objetivando o acesso à fala dos/as informantes (vale destacar que as entrevistas foram estruturadas em três blocos: leitura do termo de consentimento, aplicação do questionário fechado e realização da entrevista semiestruturada, e que esta última foi gravada e posteriormente transcrita, sendo que a análise realizada se ateve à sua forma escrita); 3) pesquisa documental: plano municipal de saúde e o plano plurianual do Município, para contextualizar como o Município normatiza as questões referentes à violência contra a mulher e as ações em saúde; 4) diário de campo, para registrar todas as impressões, sentimentos, idéias dos momentos vividos em campo, tanto na pesquisa de documentos quanto nas entrevistas.

Foram entrevistados/as os/as seguintes gestores/as das secretarias municipais de saúde: a) secretário/a titular de saúde; b) secretário/a adjunto/a; c) diretor/a de planejamento; d) diretor/a ou coordenador/a das seguintes áreas: d1) saúde da mulher; d2) DST/AIDS; d3) ações básicas; d4) acidentes e violência. Também foram entrevistadas as coordenadoras gerais das Coordenadorias da Mulher. A Coordenadoria da Mulher, instância do governo municipal, tem o papel de discutir questões de gênero e propor ações, a partir dessa discussão, de forma transversal em todas as ações do governo, sendo as questões da saúde e da violência destacadas como ações prioritárias. Assim, foram realizadas dezoito entrevistas (Porto, 2002).

O estudo, sendo de caráter descritivo, qualitativo e exploratório, não pretende aprofundar-se na discussão teórica das representações. Pretende-se identificar o que pensam os/as gestores/as sobre a saúde da mulher em situação de violência no que se 
[...] não só a mulher, a vitima, tem que ser trabalhada, como o agressor precisa também de todo

um

acompanhamento psicológico,

psicossocial, tem que passar por toda a parte, tem que ser um trabalho psicossocial, tem que essa... refere às ações demandadas para as/os psicólogas/os a partir do que falam.

A leitura do empírico foi realizada a partir de: 1) tabulação dos dados dos questionários e 2) análise do diário de campo e, principalmente, das falas, após exaustiva leitura das entrevistas transcritas. As falas foram separadas dentro de alguns grandes temas: violência contra a mulher, homem agressor, mulher agredida, ações propostas para as mulheres em situação de violência (Porto, 2002). Especificamente para este artigo, foram destacadas as representações sobre a atuação dos/as psicólogos/as e/ou a função da Psicologia.

Por fim, este estudo foi aprovado pelo Comitê de Ética em Pesquisa do Centro de Ciências da Saúde da Universidade Federal de Pernambuco, em 07/11/2001.

\section{Caracterizando os gestores e gestoras}

Os/As gestores/as podem ser caracterizados/ as como um grupo eminentemente feminino, com idade entre 34 a 52 anos, de cor branca, com formação de graduação em ciências da saúde ou ciências humanas e pós-graduação na área de saúde pública. Todos/as os/as entrevistados/as, com exceção de uma, consideram-se trabalhadores/as do SUS ou servidores/as públicos/as, mesmo quando não têm vínculo empregatício com o serviço público, mais especificamente, com a saúde. Quase todos citam filiação partidária, com história de antiga militância. Desses, todos são filiados a partidos que se nomeiam "de esquerda". A participação em movimentos sociais é menor que a participação em partido político. Dos movimentos sociais citados pelos/as informantes, a militância nos movimentos feministas e sanitarista se destacam.

\section{O que gestores/as falam sobre a violência contra a mulher e a intervenção da Psicologia}

Antes de apresentar o relato dos/as gestores/ as, é importante fazer um destaque sobre os documentos pesquisados - relatórios de gestão, planos de gestão e operativos e propostas aprovadas nas conferências municipais de saúde. Esses se referem à necessidade do estabelecimento de uma rede de atendimento à mulher em situação de violência, de realizar uma atenção integral à saúde das mulheres e ações intersetoriais de combate, prevenção e assistência à violência contra a mulher (Porto, 2002).

Entretanto, não há explicitação sobre como se dará a rede de atendimento e quais seus participantes, como será estabelecida a atenção integral dentro do próprio sistema de saúde e quais os setores que fariam parte das ações intersetoriais.

Apesar desse contexto formal, de referência para a normatização das ações, a intervenção da Psicologia é destacada pelos gestores/as como uma das ações esperadas para resolver a questão da violência contra a mulher, embora não apareça, em nenhum documento, a relação das políticas de enfrentamento à violência contra a mulher e as ações em Psicologia ou em saúde mental. Para algumas informantes, é preciso ampliar o atendimento para além da mulher agredida, sendo também necessário estendê-lo ao agressor, às crianças e adolescentes, enfim, a toda a família:

[...] não só a mulher, a vítima, tem que ser trabalhada, como o agressor precisa também de todo um acompanhamento psicológico, psicossocial, tem que passar por toda a parte, tem que ser um trabalho psicossocial, tem que essa... no caso de uma família, tem que passar por todo um trabalho, porque os filhos também, as filhas tão lá dentro desse processo; muitas vezes, acusam a mãe, porque a mãe já é agredida, e ela também é acusada por estar sendo agredida. Então, é tudo um processo que precisa ser, é um conjunto, na verdade, é um conjunto, é todo um conjunto que precisa 
ser trabalhado; não dá pra trabalhar isoladamente[...] (Rose, 34 anos).

[...] esse agressor também precisa de assistência, também precisa de um atendimento psicológico, também precisa de ver que é que está acontecendo com ele [...] (Eleonora, 52 anos).

A identificação dos casos de violência é percebida como foco de um acompanhamento psicológico. Para Carmem, a intervenção psicológica figura como um entre outros encaminhamentos que se fazem necessários e que extrapolam as ações do sistema de saúde:

A gente treinou, por exemplo, os agentes comunitários pra trabalhar a questão da violência sexista, para identificação dos casos, [...] encaminhamento, porque não só o encaminhamento pra tratamento, por exemplo, acompanhamento por uma psicóloga, pra tomar, por exemplo, no caso de, de mulheres violentadas, pra tomar a pílula do dia seguinte... [...] mas também pra o acompanhamento, por exemplo, isso é a parte que a saúde faz, mas tem a parte que é o acompanhamento legal, que é o apoio a essa mulher para ela se sentir autora do seu próprio processo de vida (Carmem, 43 anos).

A violência psicológica é pontuada abaixo como um dos tipos mais 'brandos' de violência, talvez quando comparada à violência física, que deixa marcas no corpo, ao mesmo tempo em que é descrita como uma violência que atinge a mulher de forma profunda na sua autoestima e na sua cidadania:

[...] a violência do dia a dia, que a gente chama assim: a violência calada [...] você destratar uma pessoa, assim, como se vê, por exemplo, tem a violência de você não respeitar a mulher que você é... que é uma coisa muito mais psicológica, que é muito mais branda, porque, essa violência, a gente também trata, que é a violência do desencanto, da coisa que, muitas vezes, os homens, a família... do resgate mesmo da cidadania dela, enquanto cidadã,... que isso, muitas vezes, não aparece. Se você for pra uma comunidade, você vê: fulana é nervosa. Muitas vezes, fulana perdeu a autoestima. Pronto, é a auto-estima! É a questão da auto-estima!...é... e a gente trabalha desde essa violência, que a gente chama uma violência, tem um termozinho que as feministas usam, eu não tô lembrada agora, que é a violência mais branda, até a violência mesmo, assim, a violência sexista, [...] mais consolidada no... nos tapas. Então, a gente trabalha desde o nível de fazer com que a mulher faça uma reflexão de cidadania, [...] resgata com isso também, por exemplo, quando a gente faz um atendimento multidisciplinar, você tá resgatando a autoestima [...] (Carmem, 43 anos).

[...] essa mulher que não reage à agressão é uma mulher que ela, ela já, ela foi violada e foi violentada e oprimida há muito tempo; de longa data. Ela já tem uma coisa crônica, essa ferida dentro dela já é... Já faz parte dela, ela já vive, convive com ela. Ela já não reage porque, prá ela ser humilhada, ser maltratada, ser... já... faz parte[...] (Sofia, 37 anos).

Essa repercussão na "auto-estima" é considerada, por esses/as gestores/as, como objeto de intervenção psicológica.

Eleonora destaca que a violência psicológica se dá de forma silenciosa, naturalizada, repetida e sistemática; em outras palavras, é a convivência diária com a violência.

[...] ela vai repercutir não só no espaço físico dela, quebra braço, etc. e tal, mas no espaço psicológico, do medo, do como ela reage ou não reage a essa situação [...] que tipo de assistência ela recebe, a condução que ela tem disso, mas... é... veja... o problema é o seguinte, que repercussão isso tem na saúde, [...] como a violência repercute na saúde? [...]
[...] essa mulher que não reage à agressão é uma mulher que ela, ela já, ela foi violada e foi violentada e oprimida há muito tempo; de longa data. 
essa violência psicológica, a gente observa ela de diversas formas, e uma dessas formas é a mulher não se sentir, a mulher achar que o marido tem o direito de bater nela, tem coisa pior do que isso? E isso é muito freqüente, você apanhar e achar que aquele cara tem o direito de bater em você, de não reagir, de não ter aonde contar [...] (Eleonora, 52 anos).

E, nesse entendimento, fica uma seqüência: a violência psicológica gerando transtornos para a saúde e esses transtornos demandando intervenção da Psicologia. A atuação da Psicologia é percebida como necessária nos casos de violência psicológica e na baixa auto-estima da mulher que convive com a violência. No entanto, essa percepção parece isolada de uma atuação da saúde mental como política pública. Seria algo como uma ação necessária, mas desvinculada de uma intervenção mais ampla e/ou integral da saúde mental.

Apenas Laura fala da necessidade de integração com a coordenação de saúde mental, dentre outras coordenações, para promover a interface necessária a uma atuação mais ampla para os casos de violência contra a mulher. Ela destaca que, na ânsia de criar soluções, organizam-se serviços deficientes, pela falta de profissionais da saúde mental, para atender tanto as mulheres vitimadas pela violência como os homens autores de violência:

[...] atuar nessa área de violência e saúde significa promover uma interface grande, não só com a divisão de DST/AIDS, mas também com a divisão de saúde mental. Porque ah!, muitas vezes, os serviços são criados, mas você não tem assistência psicológica e não tem também assistência de psiquiatria, e isso é necessário não apenas para as mulheres, mas também no caso dos agressores. Então, isso a gente já detectou, a gente já conversou em relação a outras gestões... [...] o nosso pensamento é buscar uma interface também com essa divisão [saúde mental], porque senão você, de fato, você não consegue uma ação eficaz. Você não pode apenas buscar reintegração social do ponto de vista econômico, da moradia ou da tentativa de vínculos, ou quebrar ciclos da violência se você não promove toda uma assistência nessa área de saúde mental (Laura, 34 anos).

Uma questão que se destaca nesse relato de Laura é que, apesar dessa necessidade premente, a interlocução, a promoção de interface, como ela chama, ainda é um "pensamento".

Tereza também ressalta a necessidade e a experiência com um trabalho integrado com profissionais da saúde mental, mas não menciona o que acontece com o trabalho que gerencia, não faz alusão a ações em conjunto com a coordenação de saúde mental como as que aconteciam na assistência, quando ela trabalhava na "ponta" do sistema:

A gente sempre teve, pelo menos, a Psicologia sempre teve presente em todas as nossas atividades; então, todo o atendimento que era feito no ambulatório a gente tinha psicólogo nos dois turnos manhã e tarde prá fazer o atendimento dessas mulheres. Eu acho que é fundamental! [...] a saúde mental, ela tem que tá presente, porque, se você não tá bem emocionalmente, você não pode é... trabalhar nem as questões do seu próprio corpo, a convivência com seu núcleo familiar, cuidar dos seus filhos, cuidar do trabalho, cuidar do marido, o cuidar de si se você emocionalmente não tá bem. Então, eu acho que não, não dá prá gente dissociar não. Acho que tem que tá junto. $\mathrm{A}$ saúde mental tem que tá acompanhando todo esse processo dentro da área da saúde da mulher, até porque eu acho, olhe! Dentro da saúde da mulher tudo passa na saúde mental (risos) (Teresa, 41 anos).

Essa questão parece importante, pois a necessidade de um trabalho da Psicologia é percebida e destacada, mas, ao mesmo tempo, no nível da gestão, da definição por políticas de saúde, a integração entre as ações para as mulheres, em especial para as mulheres em situação de violência, não está diretamente vinculada às políticas de saúde mental, mesmo 
com todos esses gestores relatando, das mais diferentes formas, a necessidade da intervenção.

Esse ponto remete a algumas reflexões: a saúde da mulher parece que ainda não integrou as questões de saúde mental como aspecto importante de atuação no processo de garantia de atendimento integral proposto tanto pelo SUS - Sistema Único de Saúde como pelo PAISM Programa de Atenção Integral à Saúde da Mulher. Dentro da divisão que gerencia a saúde da mulher, mesmo quando defende uma atenção integral às mulheres, quando considera um problema de saúde pública que demanda ações da Psicologia, a saúde mental, em seu nível de gestão, não é integrada às ações. A intervenção psicológica parece ser demandada de forma pontual, e não como parte de uma política de saúde mental. Vejamos o que diz Laura (34 anos): [...] mesmo a necessidade de buscar no atendimento psicológico de grupos, de homens e coisas do tipo, prá buscar uma ação preventiva. Acho que são ações ainda incipientes, importantes, mas acho que elas são cheias... de contradições e dificuldades muito grandes. Por exemplo, em relação a esse debate sobre abrigar ou não uma mulher ou afastar o agressor do, da casa ah! o que se tem observado é que, quando isso acontece, os homens acabam invadindo a casa [...] de supetão, de surpresa, e as mulheres, elas permanecem sobre risco. Então, isso é, acho um elemento prá que tem sido considerado de como equacionar esse atendimento em relação aos homens. Outra, por exemplo, os grupos de assistência psicológica que têm sido desenvolvidos. Tem uma experiência importante no Rio Grande do Sul, especificamente em Porto Alegre. Tem sido feita, e o que tem sido observado nessa área é que, às vezes, os homens procuram esses grupos, ou melhor, procuram essa assistência, têm dificuldades esses, esses grupos têm ou essas ONGs, ou serviços têm de criar grupos e outra coisa que se observa também é que é... os homens eles são muito motivados a participar dessas atividades, dessas reuniões, porque há... é como eles entendessem isso como uma possibilidade de reconciliação com as mulheres, e nós sabemos que, geralmente, quando ocorre a reconciliação, ah!, temporariamente, a situação não se reproduz, mas, depois de um tempo, ela volta. Então isso, acho que é parte dos desafios que a gente tem (Laura, 34 anos).

Essa afirmação de Laura traz uma questão importante para a atuação da Psicologia nesse universo que para nós, profissionais, se apresenta como uma expectativa dos outros e uma demanda de atuação: como dar conta desse aspecto subjetivo da violência de gênero contra a mulher. Dessa forma, surgem algumas perguntas: por que uma mulher permite ser agredida de várias formas e por muitos anos, e outra, da mesma classe social, idade, cor/ descendência, escolaridade, não permite? Por que um homem agride a sua esposa ou companheira, e não o colega que o humilhou ou o amigo com quem estava bebendo? Esse universo subjetivo da situação de violência aparece como um ponto ainda com muitas contradições, de difícil compreensão para a equipe multiprofissional e que é demandada, para a/o psicóloga/o, a resolução. Dessa forma, faz-se necessário entendermos qual a nossa intervenção, quais as nossas possibilidades e limites, não deixar que, com outra roupagem, se esteja "psicologizando" questões culturais ou socioeconômicas. É importante pontuar como a Psicologia pode contribuir diante de tantas expectativas:

[...] porque, quando ela vem ao serviço, vem em busca de alguma coisa. E a gente tem essa resposta prá dar? Essa resposta nem sempre é um medicamento! Mas é uma fala, é você ouvir, é encaminhar ela prá um outro profissional que ela esteja necessitando de apoio psicológico, emocional é, enfim (Teresa, 41 anos).

A demanda apresentada pela mulher ao serviço de saúde promove uma reflexão do paradigma da assistência à saúde: não é apenas a cura do corpo que se busca, não é a busca por medicamentos que motiva a procura, e sim, a necessidade de falar e de ser ouvida em seu sofrimento e, imediatamente, o profissional da escuta é identificado como a/o psicóloga/o. 
O universo da Psicologia aparece na definição, na tipologia de classificação das violências cometidas contra as mulheres, e, ao mesmo tempo, aparece como ação prioritária na prevenção e na assistência a esses casos, num primeiro momento, como forma de livrar os profissionais da saúde de enfrentar um tipo de situação da qual seus procedimentos e protocolos de atendimento não dão conta e num segundo momento, como integrante de uma rede de ações necessárias com uma demanda própria.

\section{A assistência psicológica às/aos profissionais que atendem as mulheres em situação de violência}

[...] a gente tá montando um serviço de apoio às vitimas de violência, desde a atenção médica, se for o caso, até uma, uma assistência psicológica,

judicial, legal, pra essas mulheres vítimas, no caso específico, das mulheres vitimas de violência (Rogério, 49 anos).
Outro aspecto que se destaca é a percepção de alguns/mas gestores/as da necessidade de um suporte psicológico aos profissionais que atendem a casos de violência contra a mulher. Não é fácil, é uma barra para os profissionais, então... esses acompanhamentos, esses treinamentos, a gente já tinha realizado, culminou agora com o local para ter uma referência dentro do Município para um acompanhamento psicológico dessas mulheres e trabalhadores, também.[...] Mas não é fácil lidar com isso, é uma dificuldade para os profissionais, até psicológica, mesmo, pra eles, de tá lidando às vezes conversar com a mulher que... foi vítima de violência; ela nega, no outro dia, chega com outro hematoma, com outra evidência de [que] houve violência [...](Bárbara, 44 anos).

Os/As informantes relatam algumas características dos casos de violência contra a mulher que demandam suporte psicológico para a vítima e para a equipe que atende essa vítima. Entretanto, utilizam-se de argumentos que ratificam um lugar para o atendimento psicológico como uma intervenção não rotineira. A intervenção em saúde mental parece algo necessário para esses casos de violência, mas algo não integrado, algo fora das ações em saúde e que, talvez por isso, eleve o custo do sistema.
[...] tem alguns comentários que chegam até assim: a gente tem medo inclusive que tenha, por exemplo, uma morte naquela residência; naquela expectativa, faz a denúncia, tenta mais... quando denuncia, é um risco para o próprio profissional, porque não é uma situação para você lidar, não é uma situação de saúde rotineira. Não é uma situação de saúde de problema de saúde, comum [...] porque você tem que ter profissionais habilitados para lidar com esse tipo de situação, com sensibilidade para esse tipo de situação: psicólogos, psiquiatras... Porque, às vezes, a repercussão da violência ultrapassa toda uma questão mais imediata, assim, de uma crise mais aguda, e tem umas repercussões para o resto da vida daquela pessoa, que ela vai precisar de um acompanhamento mais longo, isso para o sistema, ela vai lidando com custos maiores e com complexidades maiores, não necessariamente em tecnologia de equipamentos, mas investimento de recursos humanos mesmo [...] (Bárbara, 44 anos).

O atendimento psicológico passa a ser fundamental em espaços específicos para o atendimento da mulher em situação de violência, atendimento que se diferencia do rotineiro em saúde e que precisa de psicólogas, como relatam os/as gestores/as a seguir:

[...] nós é...estruturamos a Casa da Mulher, que inclui, entre as ações que são realizadas lá, o acolhimento, o atendimento à mulher vítima de violência, feita por psicóloga (Vânia, 43 anos).

[...] a gente tá montando um serviço de apoio às vítimas de violência, desde a atenção médica, se for o caso, até uma, uma assistência psicológica, judicial, legal, pra essas mulheres vítimas, no caso específico, das mulheres vítimas de violência (Rogério, 49 anos).

O procedimento para o atendimento à violência, ele não precisa de nenhuma sofisticação, não acrescenta nada, não precisa de, se, precisa, sim, de se capacitar uma equipe de retaguarda para fazer o atendimento psíquico-social e o atendimento psicológico em grupo é... o individual e o atendimento à família. Então, nesse 
sentido, a gente tá treinando grupos de profissionais pra se capacitar na violência (Dóris, 43 anos).

Talvez a percepção da intervenção psicológica como algo ainda não incorporado pelas ações em saúde promovam esse distanciamento das ações de saúde mental e da saúde da mulher em situação de violência.

Ao mesmo tempo, observa-se um distanciamento entre os procedimentos pensados para a intervenção nos casos de violência contra a mulher e as ações efetivamente desenvolvidas pelos/as profissionais de Psicologia da rede:

[...] a gente vê que foi feito um levantamento aqui no [departamento de] saúde mental que [...] uma assistência maior de assistência psicológica é para os...é... meninos da escola, com problemas de aprendizagem (Dóris, 43 anos).

De uma forma geral, esses/as gestores/as percebem como atendimento da saúde as conseqüências de uma agressão física. Para esses casos, os serviços de saúde, na forma como estão estruturados, poderiam dar uma resposta. Entretanto, não dariam conta do problema do ponto de vista das repercussões emocionais e psicológicas, compreendendo a questão além do sintoma físico apresentado:

[...] a população reconhece o serviço, ela pode até procurar a Delegacia da Mulher, mas ela não identifica, na saúde, um espaço pra discutir esse tipo de violência. A não ser quando tem a agressão física no sentido do corte, da fratura, que aí ela procura para atender aquele agravo, mas não discute com o sistema o que ela está sentindo em relação a isso e que forma de acompanhamento que ela precisaria ter multidisciplinar... até pra poder reagir pra esse tipo de violência [...] a gente tem que quebrar esse preconceito, nos dois lados, e os profissionais da rede não estão preparados também para lidar com isso, eles podem tratar até a ferida proveniente disso, mas não sei se estão preparados, não tão preparados para tratar outra ferida, que é a perda psicológica, a estrutura psíquica da pessoa, que se sujeita a passar por isso que não tem, naquele momento, escolhas diferentes (Sabrina, 40 anos).

Os altos custos, para o sistema de saúde, dos casos de violência contra a mulher são pontuados por Saulo como justificativa para a definição por políticas para as mulheres em situação de violência. Nesse contexto, ele também salienta a repercussão psicológica como a que se destaca:

As mulheres vítimas de violência, elas representam um contingente significativo que... é... demandam serviços de saúde que demandam gastos, enfim, que repercutem violentamente em todos os aspectos da saúde da mulher do ponto de vista psicológico, do ponto de vista orgânico mesmo, não é? (Saulo, 44 anos).

Por fim, Pedro destaca os casos onde o encaminhamento ao serviço de Psicologia pode não ser aceito, o que faz o sistema de saúde ter que pensar em uma outra intervenção dentro das ações "de saúde" para resolver o caso.

Além de ser percebida como uma intervenção fora do sistema de saúde, parece que a ação clássica da Psicologia - a intervenção clínica própria da esfera privada - não funciona, e outras ações precisam ser pensadas.

A partir do momento que vão surgindo os casos, você tem que saber como... Geralmente é enviado pra o psicólogo, que a pessoa pode não querer ir. Então nós, que atendemos na ponta, temos que saber o que é que a gente vai fazer pra curar aquele mal, não pra botar uma coisa... simplesmente não resolve a... violência (Pedro, 44 anos).

\section{Considerações finais}

Pode-se começar essa reflexão a partir da fala de Pedro. Ele destaca um aspecto interessante, quando a indicação, para o acompanhamento psicológico, não é desejada pela paciente/usuária que precisa de uma intervenção em saúde. De 
forma implícita, a intervenção psicológica aparece como uma ação especializada que precisa de uma decisão da paciente. Caso esta aceite, terá o atendimento e a solução do seu caso. No entanto, tem-se um problema para o sistema de saúde quando a usuária não deseja esse atendimento. Nesse caso é que esse sistema precisa dar uma resposta dentro do escopo das ações em saúde. Nesse contexto, a intervenção psicológica parece ser pensada como algo fora das ações de saúde necessárias para solucionar problemas que chegam às unidades de saúde. A intervenção em Psicologia não está vinculada às ações das políticas de saúde da mulher como uma ação de saúde mental.

Esse aspecto também aparece na ausência de referência, nos planos e relatórios de ação, da necessidade ou da importância da intervenção psicológica ou em saúde mental. O que chama mais a atenção, principalmente quando comparamos o que está posto no planejamento e o que é falado pelos/as gestores/as. Se a intervenção em Psicologia é tão importante quanto os/as gestores/as apresentam, por que as ações para a saúde da mulher em situação de violência - cujo pressuposto é o atendimento em rede e a atenção integral - não destacam a relação com as ações em saúde mental?

Dessa forma, o papel da/o psicóloga/o apresenta-se ainda não integrado às ações de saúde quando estas são pensadas do ponto de vista da saúde como sistema e política pública. A Psicologia aparece quando se demandam ações que o sistema de saúde não soluciona. Nesse ponto, a percepção desses gestores de uma necessidade premente da intervenção psicológica nos casos de violência contra a mulher merece alguns comentários:

- A "psicologização", ou seja, tratar como transtorno psicológico uma questão cultural, social e/ou econômica apresenta-se como um ponto por demais negativo ao buscar a Psicologia como forma de "empurrar" um problema que não consegue solução ou um problema de menor valor, de menor importância para a saúde, como são percebidos os casos de violência contra a mulher, que passa a ser demandado à/o profissional da Psicologia. Os/as informantes ilustram isso em seus relatos, quando se referem à intervenção da Psicologia como último recurso, isso porque, para eles/as, dentro das possibilidades da intervenção em saúde, nada mais poderia ser feito.

Tomando essa posição, os profissionais da saúde se eximem de entender o fenômeno complexo da violência contra a mulher e de reformular suas ações de forma a colaborar no processo de prevenção e assistência a esses casos.

- Faz-se necessário rever qual o papel de um/a psicólogo/a no Sistema Único de Saúde. Parece existir uma dificuldade, por parte de psicólogas/ os, de atuação como um/a profissional da equipe multidisciplinar de saúde. Essa dificuldade é resultante de uma formação dirigida à intervenção para clínica privada. Quando chega a uma instituição, a/o psicóloga/o começa a atuar de uma forma isolada, afastada da dinâmica institucional - ou pensando que está. Esse afastamento alimenta o cenário, percebido pelos/ as gestores/as da saúde, no qual as ações de saúde mental são outras ações separadas das 'ações de saúde'. Atuando de forma isolada, fazendo intervenções de psicoterapia, apenas, a/o psicóloga/o fica deslocada/o de um programa de saúde mental mais amplo, de ações articuladas entre as/os profissionais da categoria e os outros profissionais da saúde. Isso se revela na fala dos/as gestores/as, quando mais de $70 \%$ dos 18 gestores/as entrevistados/as destacam a importância da assistência psicológica às mulheres em situação de violência; no entanto, existe a expectativa da ação de uma/um ou, no máximo, dois profissionais da Psicologia, e não uma integração das ações de saúde da mulher e de saúde mental. Por fim,

- Definir qual o papel da/o psicóloga/o e quais as interfaces que se fazem necessárias com as instâncias que pensam e definem a política de saúde mental do Município (Estado ou União) na relação com a violência contra a mulher, problema grave de saúde pública, e que tem na imagem da Psicologia o elemento determinante para garantir a resolubilidade dos casos. 
Fica para as/os psicólogas/os a reflexão sobre um campo de trabalho que está crescendo e necessitando de intervenção. A política de saúde mental precisa também oferecer apoio psicológico às mulheres em situação de violência e às equipes de atendimento, num trabalho de 'retaguarda' para os/as profissionais da saúde, de assessoramento nas discussões de saúde mental e de inclusão da saúde mental como um aspecto significativo da saúde. Nesse contexto, a Psicologia, como uma ciência e uma profissão, pode dar importantes contribuições na mudança de paradigmas: da saúde, da saúde pública e da saúde mental.

Psicóloga (UFPE), Especialista em Psicologia clínica e Mestra em Saúde Coletiva (UFPE). Pesquisadora vinculada ao Núcleo Família, Gênero e Sexualidade-FAGES/UFPE e professora do curso de Psicologia da

Faculdade da Amazônia Ocidental - FAAO.

Representante do Conselho Regional de Psicologia 1ạ Região-Seção Acre.

Rua Álvaro Rocha, 101. Conjunto Universitário I, quadra 45, Distrito Industrial, Rio Branco - AC -

Brasil. CEP - 69915-300. Telefone: (68) 32292812 / 99710821.

E-mail: madgeporto@ig.com.br, madgepsi@ibest.com.br

Recebido 05/01/04 Reformulado 21/02/06 Aprovado 14/06/06

BOZON, M. Amor, Sexualidade e Relações Sociais de Sexo na França Contemporânea. Revista Estudos Feministas, ano 03. Florianópolis, 1995, pp. 122- 135 .

BRANDÃO, E. R. Violência Conjugal e o Recurso Feminino à Polícia. In: Bruschini, C.; Hollanda, H. B. (orgs.). Horizontes Plurais: Novos Estudos de Gênero no Brasil. São Paulo: Editora 34/Fundação Carlos Chagas, 1998, pp. 51-84.

BOCK, A. M. B. Eu Caçador de Mim: Pensando a Profissão de Psicólogo. In: Spink, M. J. (org.). O Conhecimento no Cotidiano: as Representações Sociais na Perspectiva da Psicologia Social. São Paulo: Brasiliense, 1995, pp. 280-291.

CAMARGO, M. Violência e Saúde: Ampliando Políticas Públicas. Jornal da Rede Saúde, n. 22. São Paulo, 2000, pp. 6-8.

D'OLIVEIRA, A. F.; SCHRAIBER, L. B. Violência Doméstica como Problema para a Saúde Pública: Capacitação dos Profissionais e Estabelecimento de Redes Intersetoriais de Reconhecimento, Acolhimento e Resposta ao Problema. Trabalho apresentado no VI Congresso Brasileiro de Saúde Coletiva. Salvador, Brasil, set. 2000.Anais. CD-rom.

FRANCO, I. R. Mulheres em Situação de Violência Doméstica: Produção e Enfrentamento do Fenômeno. Trabalho apresentado no VI Congresso Brasileiro de Saúde Coletiva. Salvador, Brasil, set. 2000. Anais. CD-rom.

GUARESCHI, N. M. F. A Criança e a Representação Social do Pode e Autoridade: Negação da Infância e Afirmação da Vida Adulta. In: Spink, M. J. (org.). O Conhecimento no Cotidiano: as Representações Sociais na Perspectiva da Psicologia Social. São Paulo: Brasiliense, 1995, pp. 212-233.

GIFFIN, K. Violência de Gênero, Sexualidade e Saúde. Cadernos de Saúde Pública, n. 10. Rio de Janeiro, 1994, pp. 146-155.

HEILBORN, M. L. Gênero e Condição Feminina: uma Abordagem Antropológica. In: Neves, M. G. R. Mulher e Políticas Públicas. Rio de Janeiro: IBAMA/UNICEF, 1991, pp.23-38.
HEISE, L.; PITANGUY, J.; GERMAIN. A. Violence against Women: the Hidden Health Burden. Washington, D.C: The International Bank for Reconstruction and Development/The World Bank, 1994.

JOVCHELOVITCH, S. Representações Sociais e Esfera Pública: a Construção Simbólica dos Espaços Políticos no Brasil. Petrópolis, RJ: Vozes, 2000

LACERDA, E. et al. O SUS e o Controle Social: Guia de Referência para Conselheiros Municipais. Brasília: Ministério da Saúde, 1998.

PORTO, M. A Saúde da Mulher em Situação de Violência: o que Pensam os Gestores e Gestoras Municipais do Sistema Único de Saúde? Dissertação de Mestrado em Saúde Coletiva. Universidade Federal de Pernambuco, Recife, 2002.

PORTO, M.; MACCALLUM, C. ; SCOT, R. P. e MORAIS, H. M. M. A Saúde da Mulher em Situação de Violência: Representações e Decisões de Gestores/as Municipais do Sistema Único de Saúde. Cadernos de Saúde Pública, vol. 19, supl. 2. Rio de Janeiro, 2003, pp.243-252.

SCHRAIBER, L. B; D'OLIVEIRA, A. F. L. P. Violência contra a Mulher: Interfaces com a Saúde. Interfaces: Comunicação, Saúde, Educação, n. 5. 1999, pp. 11-27.

SCHRAIBER, L. B; D'OLIVEIRA, A. F. L. P; STRAKE, S. S. e LIBERMAN, M. D. Violência contra a Mulher e Políticas de Saúde no Brasil: o que Podem Fazer os Serviços de Saúde? São Paulo: Departamento de Medicina Preventiva/Faculdade de Medicina/USP. (s/d) (mimeo.Texto para curso).

SPINK, M. J. P. Psicologia Social e Saúde: Práticas, Saberes e Sentidos. Petrópolis, RJ: Vozes, 2003.

VARGAS, J. D. Estupro: que Justiça? Cadernos Themis-Gênero e Direito, ano 3, n. 3. Porto Alegre: 2002, pp. 55-78.

\section{Referências}

